\title{
Failure analysis of a 40 ton crane hook at a Hot Strip Mill
}

\author{
Souvik Das*, Goutam Mukhopadhyay, Sandip Bhattacharyya
}

R\&D and Scientific Services, Tata Steel Limited, Jamshedpur-831 001, India

*Corresponding author: Address: Metallurgical Laboratories and QA Group, R\&D and Scientific Services, Tata steel Ltd., Jamshedpur 831 001, India Tel.: +91 809284714; fax: +91 657234395.

E-mail address souvik.das@tatasteel.com

\begin{abstract}
:
There have been accounts of repeated failure of crane hooks at the coil yard of a Hot Strip Mill which pose a serious threat to safety in the area. More than 4 hooks failed in less than 5 years. The crane hook (rated for $36000 \mathrm{~kg}$ ) failed from the threaded shank while lifting a load of $18143 \mathrm{~kg}$. The metal in the hook was revealed by chemical analysis to be killed IS: 4367 20C15 steel. The hook rod failed from a step where there was a cross sectional change and the locations were associated with machining and chatter marks. Such cross-sectional changes are the potential sites of stress concentrations leading to crack initiations. Fracture surfaces of broken pieces of hook reveal initiation of beach marks from both sides with granular rough surface at the middle of fracture zone. Beach marks initiated from both sides indicate origin of reverse bending fatigue. Distinct granular rough zone at the middle is due to final brittle fracture. Microstructure of the polished sample revealed numerous inclusions which indicate that the steel was not clean .Such a huge number of inclusions are not desirable as they can act as stress concentration sites and lead to fatigue crack initiation. Etched microstructure of failed hook reveals coarse cast structure having inhomogeneous microstructure with a mixture of ferrite and pearlite (which meant lower fatigue strength). This inhomogeneous coarser cast structure is outcome of lower reduction ratio during rolling followed by improper heat treatment process. The fracture was concluded to have occurred due to stress concentration from the step region due to inferior material (Inclusion and Improper Heat treatment process). Preventive maintenance and condition monitoring procedures should be applied to identify and minimize the risk(s) Establishment of an NDT procedure for regular basis inspection of the structural members (welded joints and hookshaped steel rods during incoming inspection and in-service).
\end{abstract}

Key Words: Crane Hook; Hot Strip Mill; Beach marks; cast structure; Fatigue 


\section{Introduction}

Crane hooks are highly liable components and are always subjected to premature failure due to accumulation of unwanted stresses which can eventually lead to its failure. Crane hooks are the primary components used in industries and constructional sites to elevate the heavy load. A crane is a machine, equipped with a hoist, wire ropes or chains and sheaves used to lift and move heavy material. Cranes are mostly employed in transport, construction and manufacturing industry. Overhead crane, mobile crane, tower crane, telescopic crane, gantry crane, deck crane, jib crane, loader crane are some of the commonly used cranes. A crane hook is basically a hoisting fixture designed to engage a ring or link of a lifting chain or the pin of a shackle or cable socket. Catastrophic failure of carne hook is one of the main reasons for industrial disaster [1-4]. In this study a 40 ton crane hook has been analysed which failed during lifting of 24 ton coil at a Hot Strip Mill (HSM). There was no human loss due to this incident but it had huge potential for fatal accident. There have been accounts of repeated failure of crane hooks at the coil yard of HSM which pose a serious threat to safety in the area [5]. More than four hooks failed in less than 5 years. The objective of this study is to find out the root cause of the failure so that proper actions can be taken to prevent the reoccurrence of such failures.

\section{Investigation Methods and Results}

\section{Visual Observation}

Overall view of the sample referred for analysis is shown in Fig. 1(a). The hook failed from a step where there was a cross sectional change (Fig. 1b); rough-machining marks and chatter marks were observed near the location of failure (Fig.1c). Such locations involving crosssectional change are the potential sites of stress concentrations leading to crack initiations. Fracture surfaces of broken pieces of hook reveal presence of beach marks from both sides with granular rough surface at the middle of fractured zone (Fig. 1d). Beach marks initiated from both sides indicate origin of reverse bending fatigue. Distinct granular rough zone at the middle is due to final brittle fracture. 

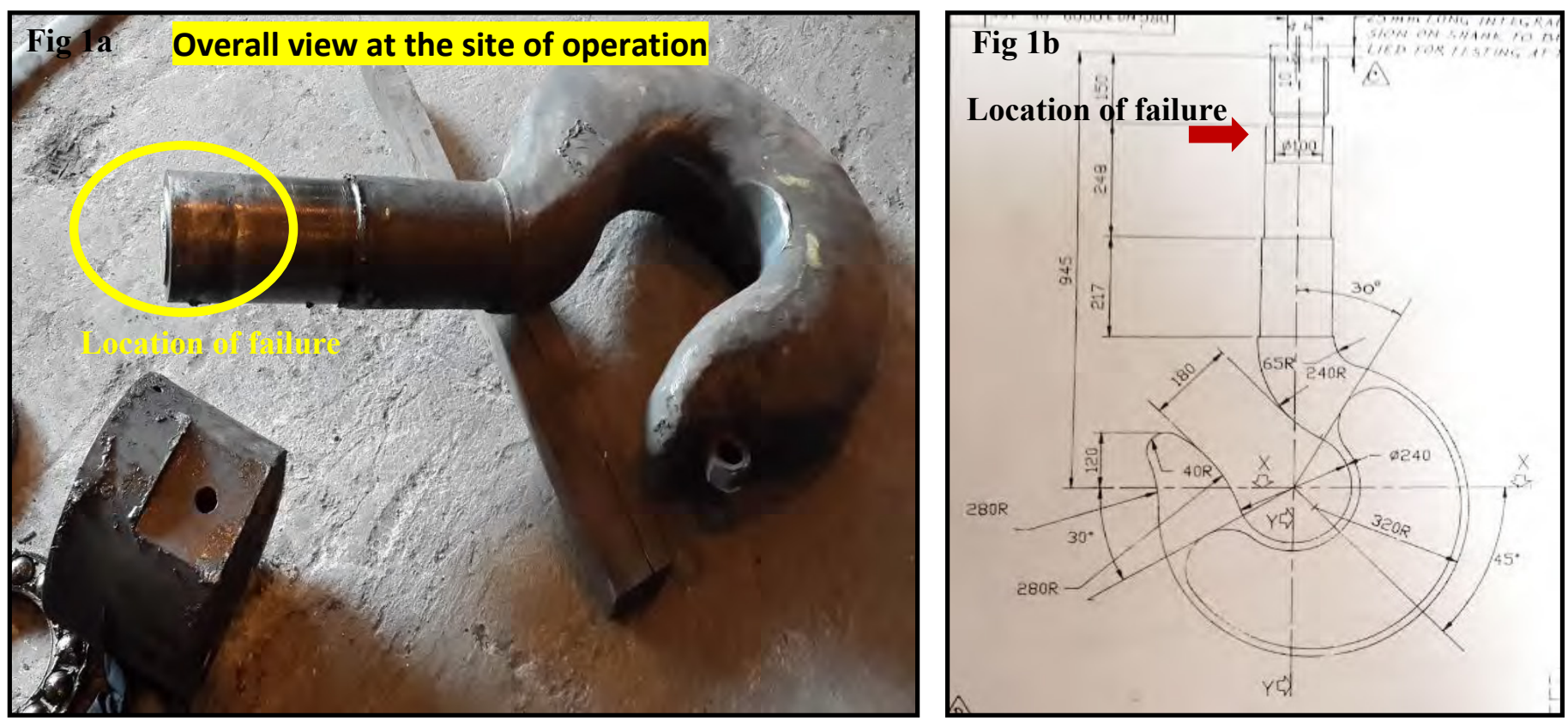

Fig. 1(a) overall view of failed hook at the site of operation (b) shows the engineering drawing of the hook with the location of failure.
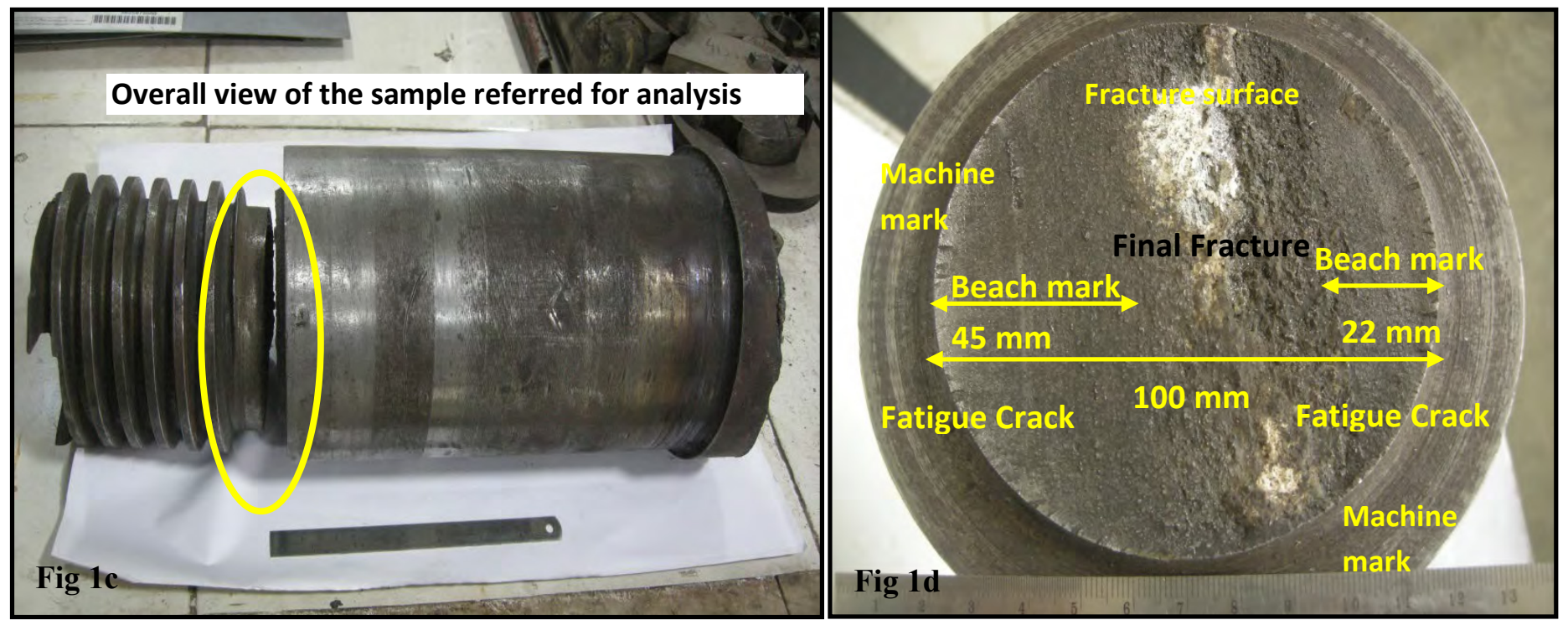

Fig. 1(c) Overall view of the sample referred for analysis, (d) Closer view of fracture surface of hook

\section{Chemical Analysis}

The chemical analysis of the failed hook sample was carried out by ICP spectroscopy. The chemistry of the failed hook matches with IS: 4367 20C15 grade of steel which was specified in the drawing. The chemical compositions of the failed sample are compiled in Table 1. 
Table 1: Chemical Analysis (Wt. \%):

\begin{tabular}{|c|c|c|c|c|c|c|c|c|c|c|c|c|}
\hline Sample & C & Mn & S & P & Si & V & Al & Ti & Cr & Mo & Cu & Ni \\
\hline Hook & 0.16 & 1.31 & 0.040 & 0.053 & 0.11 & 0.0003 & 0.001 & 0.0007 & 0.022 & 0.001 & 0.009 & 0.012 \\
\hline IS:4367 & $0.16-$ & $1.30-$ & - & - & $0.10-$ & -- & -- & -- & -- & - & -- & -- \\
20C15 grade & 0.24 & 1.70 & & & 0.35 & & & & & & & \\
\hline
\end{tabular}

\section{Experimental Procedure}

The failed hook was collected from the plant for investigations. The samples were cleaned with acetone to remove dirt for visual examination prior to metallographic sample preparation. Transverse and longitudinal specimens were made from the fractured end of the failed samples for conducting optical microscopic examination. These samples were individually mounted in conductive mounting and polished by conventional metallographic techniques for scratch free surface. The polished samples were etched in $3 \%$ nital solution (3 $\mathrm{mL} \mathrm{HNO}_{3}$ in $97 \mathrm{~mL}$ ethyl alcohol), and both un-etched and etched samples were examined under an optical microscope. The hardness of different location was observed in the failed samples was determined in a pneumatically controlled automatic micro hardness tester (LecoLM247 AT). An applied load of 100gf was used during testing, and several indentations were made to determine the hardness of the failed component. Field Emission Gun Scanning Electron Microscopy (FEG-SEM) of the samples was also carried out to identity fracture surface at higher magnifications. The analyses were performed at $15 \mathrm{keV}$ accelerating voltage and $5^{10-8}$ A probe current.

\section{Fractography}

Field Emission Gun Scanning Electron Microscopy (FEG-SEM) of the samples was also carried out for fractography analysis to find out the mode of failure. The analyses were performed at $15 \mathrm{keV}$ accelerating voltage and $5^{10-8} \mathrm{~A}$ probe current. The extent of fatigue zone and striation spacing is consistent to high cycle fatigue (HCF). FEG-SEM revealed cleavage nature of the final fracture surface suggesting brittle fracture due to over load. 


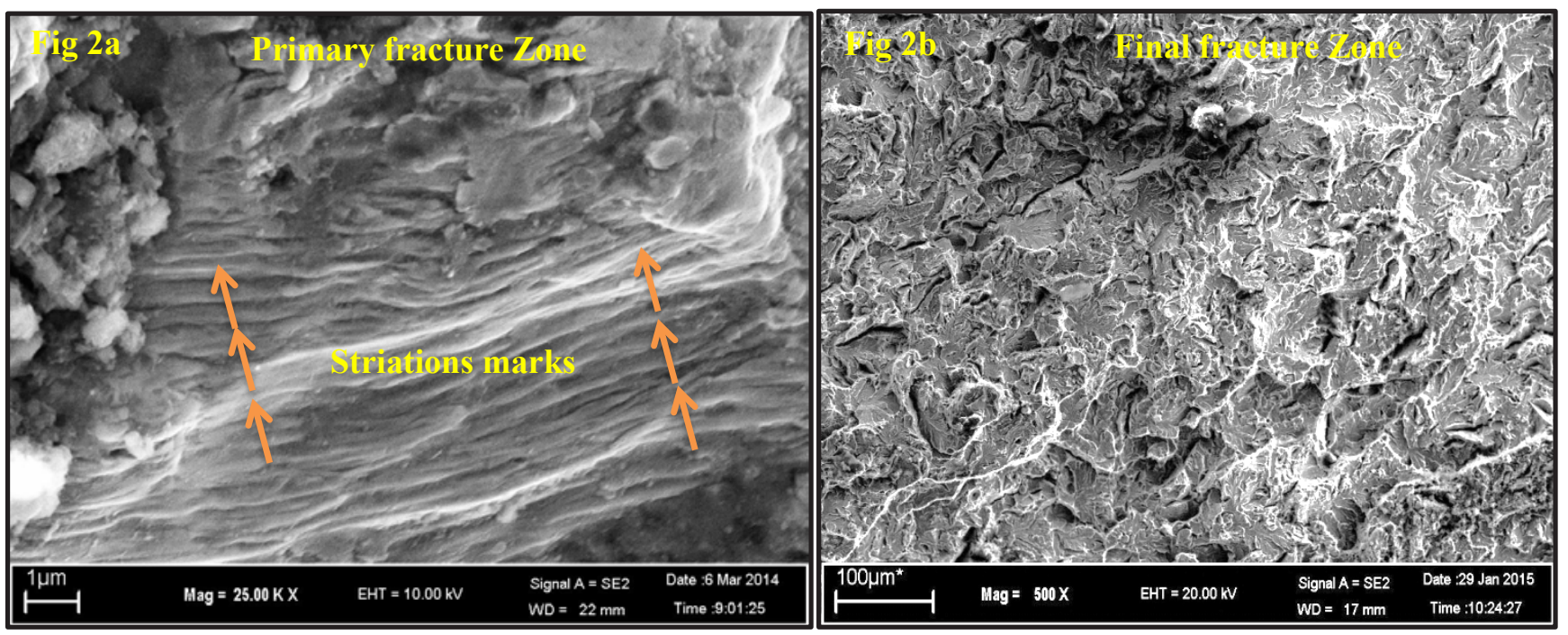

Fig 2a. FEG-SEM analysis shows fatigue striations marks in the primary fracture surface, (b) showing the microstructure of final overload area (fast crack growth zone).

\section{Microstructure Analysis}

Microstructure of the polished sample revealed numerous inclusions which indicate that the steel was not clean (Fig. 3a). Such a huge number of inclusions (as shown in Table 2) are not desirable as they can act as stress concentration sites and may lead to fatigue crack initiation.

Etched microstructure of failed hook as shown in Fig. 3(b-c) reveals coarse cast structure having inhomogeneous microstructure with a mixture of ferrite and pearlite. This inhomogeneous coarser cast structure is outcome of lower reduction ratio during rolling followed by improper heat treatment process.

\section{. Table 2: Inclusion rating:}

\begin{tabular}{|c|c|c|c|c|}
\hline Sample & Type A & Type B & Type C & Type D \\
& $\mathbf{( T / H )}$ & $\mathbf{( T / H )}$ & $\mathbf{( T / H )}$ & (T/H) \\
\hline Hook & $\mathbf{2 . 0 / 1 . 0}$ & $0.0 / 0.0$ & $0.0 / 0.0$ & $0.5 / 0.0$ \\
\hline
\end{tabular}

Inclusion rating of the failed component was carried out as per ASTM E-45.Un-etched microstructure of hook shows that thin and thick sulfide (Type A) inclusions ( Conformed by 
EDS analysis) are present with a severity of 2.0 and 1.0 respectively. Some inclusions of Type D (oxides) are observed with a severity of 0.5 .
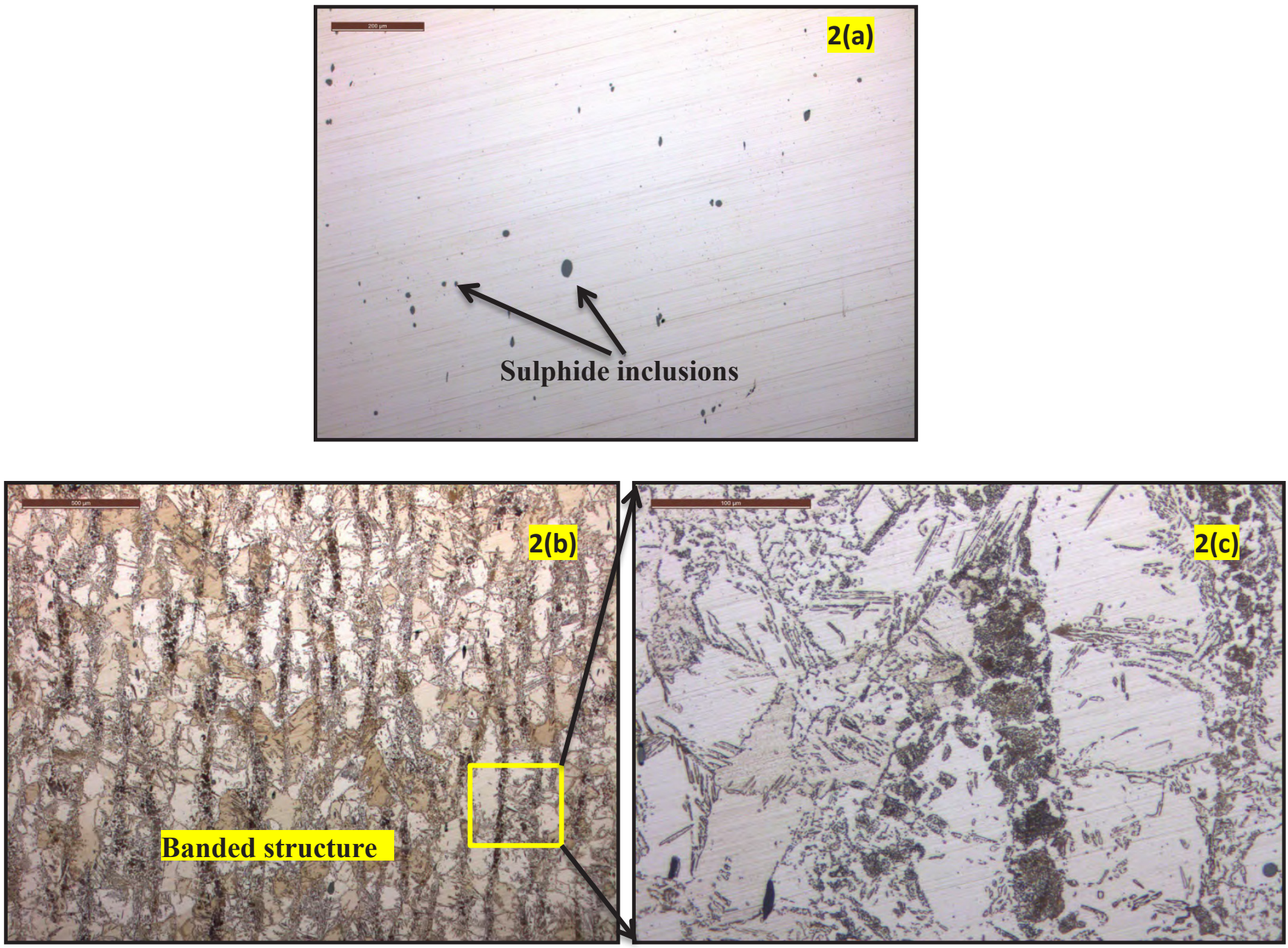

Fig. 3: (a) Un-etched microstructure of hook (b -c) Etched microstructures of hook sample at different magnifications.

\section{X-Ray Mapping of the Different Phases}

X-ray mapping was carried out on the failed hook sample to determine the elemental concentration in the inclusion (Fig. 4). Elemental analysis under SEM reveals that the inclusions were observed to be rich in Sulphur (S) and Manganese (Mn) indicating them to be manganese sulphide inclusions. 


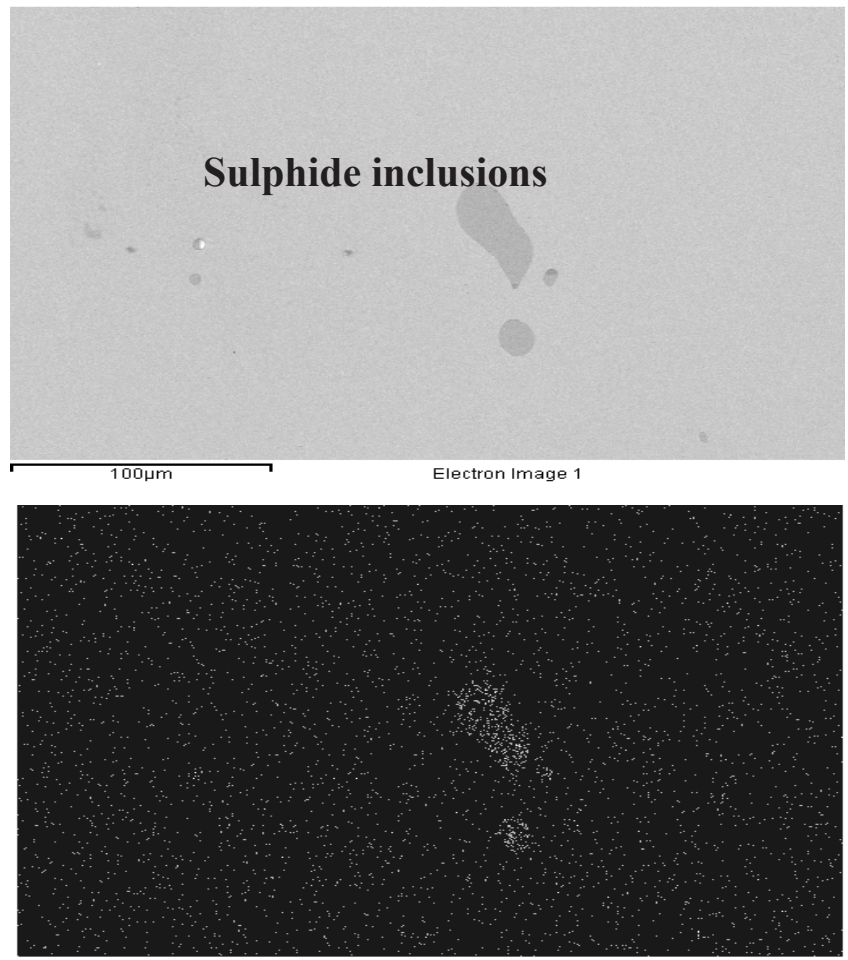

Mn Ka1

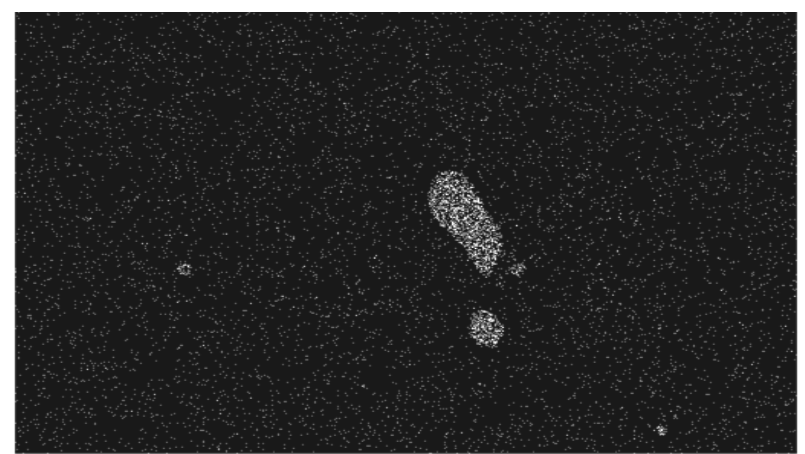

$\mathrm{S} \mathrm{Ka} 1$

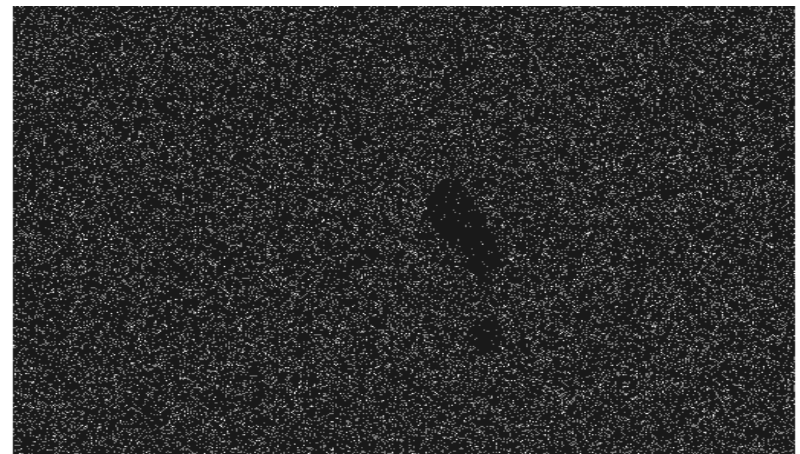

Fe Ka1

Fig. 4 showing X-ray mapping of failed hook sample.

\section{Mechanical Property Analysis}

Vickers hardness tester was used to analysis the hardness of the failed sample. The average hardness of the hook was found to be 163 BHN. But the Yield Strength (Y.S) and the UTS (Ultimate Tensile Strength) of the hook was found significantly lower than the specification due to inhomogeneous coarser cast structure as shown in Table 3.

Table 3: Result of Mechanical properties:-

\begin{tabular}{|c|c|c|c|c|c|}
\hline Sample ID & Hardness & YS & U T S & \%EL & $\begin{array}{c}\text { Avg. Impact } \\
\text { Value } \\
\text { (BHN) } \\
\text { (Joules) }\end{array}$ \\
\hline Hook & 163 & $\mathbf{2 1 4 . 5}$ & $\mathbf{4 4 3}$ & 32 & 54.9 \\
\hline $\begin{array}{c}\text { IS:4367 } \\
\text { (MC15 grade }\end{array}$ & 200 & 400 & $\mathbf{6 0 0 - 7 5 0}$ & 18 & $\mathbf{5 0}$ \\
& Max & Min. & & Min. & Min. \\
\hline
\end{tabular}

\section{Discussion}

There have been accounts of repeated failure of crane hooks at the coil yard of Hot Strip Mill which pose a serious threat to safety in the area. More than 4 hooks failed in less than 5 years. Fracture surfaces of broken pieces of hook reveal initiation of beach marks from both sides 
with granular rough surface at the middle of fracture zone. Beach marks initiated from both sides (Area 1 and Area 2) indicate origin of reverse bending fatigue.

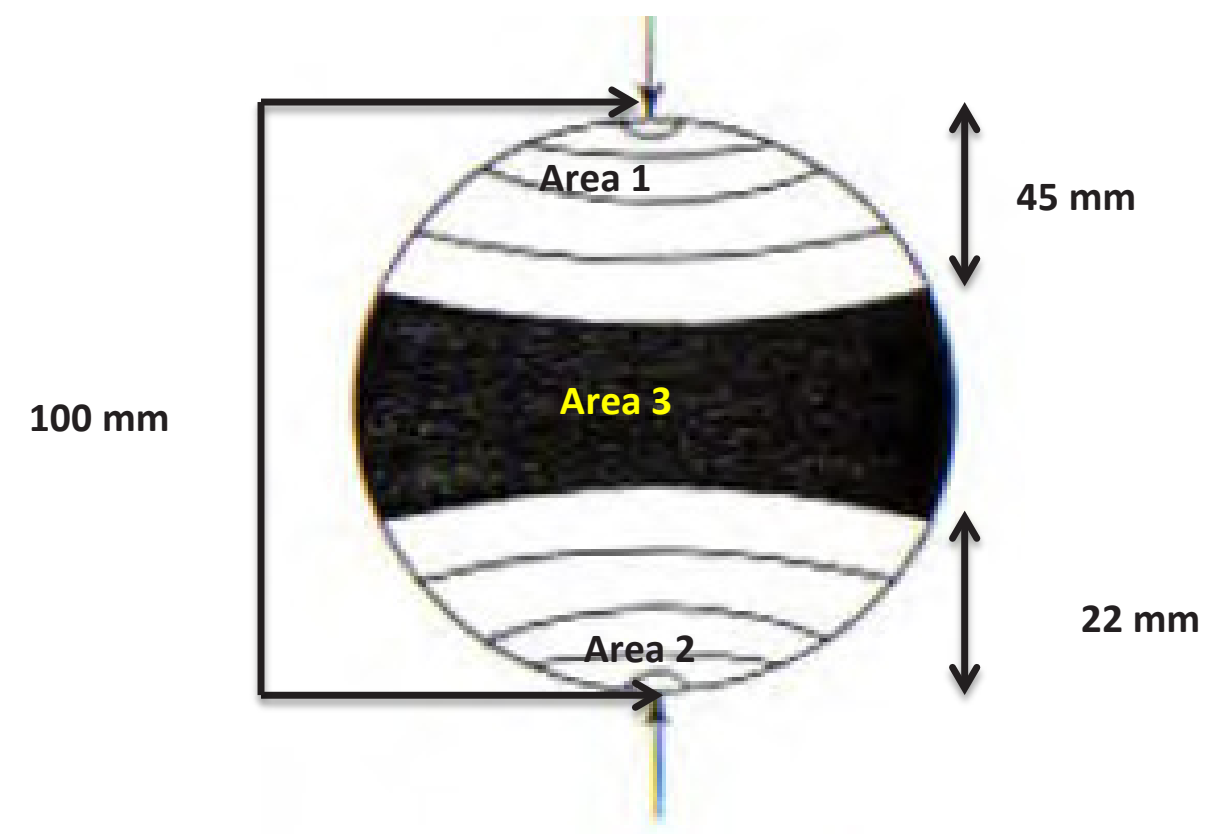

Fig 5: Schematic illustration of the failed hook showing the approximate location of the fracture Calculation of Area 1 (Fatigue Failure)

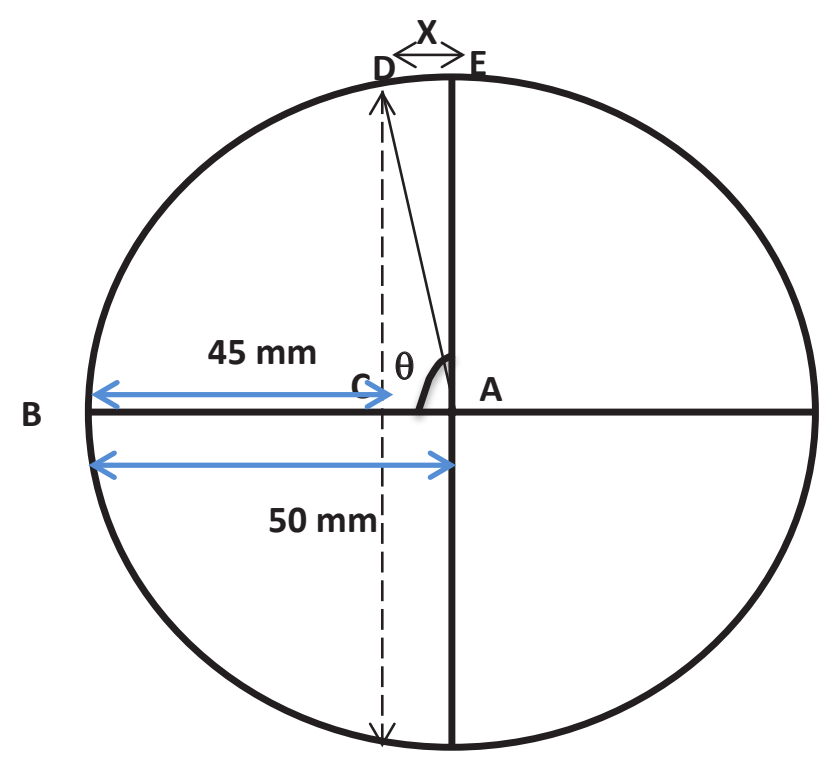

From the drawing we found the radius of the failed sample is $50 \mathrm{~mm}$ and the length of the first fatigue 1 is $45 \mathrm{~mm}$ (BC).Lets take distance of $\mathrm{x}$ to be zero. Thus $\mathrm{D}$ is equal to $\mathrm{E}$

Now Length of $C D=\sqrt{ }\left(50^{2}-5^{2}\right)=49.74 \mathrm{~mm}^{2}$

And $\operatorname{Cos} \theta=\mathrm{AB}-\mathrm{BC} / 50=5 / 50$. 
$\therefore \theta=84$ degree.

Now Total Area $\left.1=2\left[(\theta / 2 \Pi) * \Pi^{*} \mathrm{R}^{2}\right)-(1 / 2 * 49.7 * 5)\right] \mathrm{mm} 2$

\section{2}

Thus total area of Fatigue Area 1 is $3414 \mathrm{~mm}$.

2

Form this way we have calculated the total area of Fatigue Area 2 is $1456 \mathrm{~mm}$.

Now Brittle fracture Area is (Area 3$)=\Pi * 502-($ Area $1+$ Area 2$)$

$$
=2980 \mathrm{~mm}^{2} \text {. }
$$

Thus the area of final fracture is small, approximately $30 \%$ of total area, indicating that the material was in-adequate for the applications.

This indicates the hook underwent cyclic bending stresses [6] at the fracture site. Distinct granular rough zone at the middle is due to final brittle fracture (Area 3). The hook rod failed from a step where there was a cross sectional change. Such locations involving crosssectional change are the sites of stress concentrations leading to crack initiations which thereby lead to final failure by the propagation of crack under fatigue mode. Microstructure of the polished sample revealed numerous inclusions which indicate that the steel is not clean. Such a huge number of inclusions are not desirable as they can act as stress concentration sites and might lead to fatigue crack initiation. Etched microstructure of failed hook reveals coarse cast structure having inhomogeneous microstructure with a mixture of ferrite and pearlite. This inhomogeneous coarser cast structure is outcome of lower reduction ratio during rolling followed by improper heat treatment process. Elemental analysis under SEM reveals that the inclusions were found to be rich in Sulfur (S) and Manganese (Mn) indicating them to be manganese sulphide inclusions. The hardness of the hook was found satisfactory as per drawing. But the hardness seems to be lower for the application, thus the specification should be reviewed. The Y.S and the UTS of the hook found significantly lower than the specification due to inhomogeneous coarser cast structure. 


\section{Conclusion}

The 40 ton hook of crane failed in fatigue mode from the step due to inferior material. Life of the hook was shortened considerably because the material was in inhomogeneous coarser cast condition, which resulted in low fatigue strength.

\section{Recommendations}

- Heat Treatment: The crane hook should normalize properly after forging to produce the most desirable structure.

- Health monitoring of plant equipment: Preventive maintenance and condition monitoring procedures should be applied to identify and minimize the risk(s) Establishment of an NDT procedure for regular basis inspection of the structural members (welded joints and hook-shaped steel rods during incoming inspection and in-service).

\section{References:}

[1] F.L. Jamieson: Fatigue Fracture of a 1020 Steel Crane Hook Failures of Lifting Equipment, Failure Analysis and Prevention, Vol 11, ASM Handbook, ASM International, 1986, p $514-528$

[2] Roe, G.J., Bramfitt, B.L.: ASM Handbook, Properties and Selections; Irons, Steels, and High Performance Alloys, vol. I, Notch Toughness of Steels. ASM, Metals Park, OH (1990)

[3] Lu, S., Su, J., Liao, S., Wang, B., Yu, L., Jiang, Y., Wen, S.:Finite element analysis on fatigue failure prediction of a rear axle housing of vehicle based on cosmos. Appl. Mech. Mater. 121(126), 843-848 (2012)

[4] Qinghua, M., Huifeng, Z., Fengiun, L.: Fatigue failure fault prediction of rear axle housing excited by random road roughness. Int. J. Phys. Sci. 6, 1563-1568 (2011)

[5] Asi, O.: Fatigue failure of a rear axle shaft of an automobile. Eng. Fail. Anal. 13, 1293-1302 (2006).

[6] Souvik Das, GoutamMukhopadhyay, Sandip Bhattacharyya.: Failure analysis of axle shaft of a fork lift: Case Studies in Engineering Failure Analysis 3 (2015) 46-51 